Recepción: 20 / 12 / 2017

Aceptación: 15 / 02 / 2018

Publicación: 21 / 04 / 2018
Ciencias Jurídicas

Artículo de Revisión

\title{
La legítima defensa como causa de justificación o exclusión de la antijuricidad
}

\section{The legitimate defense as a cause of justification or exclusion of anti-currency}

\author{
A defesa legítima como causa da justificação ou exclusão da ilegalidade
}

\author{
Merck M. Benavides-Benalcázar ${ }^{\mathrm{I}}$ \\ mbenavides@uce.edu.ec \\ Borman R. Vargas-Villacres II \\ bormanvargasv@uta.edu.ec \\ María G. Acosta-Morales III \\ mg.acosta@uta.edu.ec
}

Correspondencia: mbenavides@uce.edu.ec

${ }^{\text {I }}$ Docente, Universidad Central del Ecuador, Quito, Ecuador.

${ }^{\text {II }}$ Docente, Universidad Técnica de Ambato, Ambato, Ecuador.

${ }^{\text {III }}$ Docente, Universidad Técnica de Ambato, Ambato, Ecuador. 


\section{Resumen}

La concepción jurídico-penal de la legítima defensa, constituye una causa de justificación o exclusión de la antijuricidad, que tiene como finalidad proteger un bien jurídico de la persona que se defendía de una agresión actual e ilegítima, utilizando un medio racional para repelerla y sin que exista provocación por parte del que defiende un derecho propio o ajeno. Se analizan desde el punto de vista doctrinario y jurídico los requisitos de la legítima defensa y su contextualización a fin de lograr una compresión integral de esta institución jurídica y su correcta utilización por los operadores de justicia. Este trabajo es de mucha relevancia en la actualidad, considerando que es una figura jurídico-penal, muy controvertida para los operadores de justicia en materia penal, tomando en cuenta que algunos aspectos son eminentemente subjetivos y que la legislación ecuatoriana está regulada para defender derechos propios del que se defiende o de terceras personas, sin embargo de lo cual en otras legislaciones, tales como la argentina y colombiana, a pesar de tener aspectos similares con la ecuatoriana, en esta última no se encuentra regulado la legítima defensa para defender la propiedad privada, lo que se encuentra debidamente regulada en las legislaciones de los dos países antes referidos, aspecto que es muy controvertido ya que en este caso se enfrentan dos derechos fundamentales, el uno que es la propiedad privada y por otra parte que puede ser la integridad física o la vida de la persona que ingresa al domicilio de la persona que defiende el derecho de propiedad.

Palabras claves: Legítima defensa, exclusión de antijuricidad, bien jurídico, agresión actual e ilegítima, necesidad racional, falta de provocación. 


\section{Abstract}

The criminal legal conception of legitimate defense constitutes a cause of justification or exclusion of unlawfulness that aims to protect the legal asset of the person who defends himself against a current and illegitimate aggression, using reasonable means to repel it and without provocation by the person who is defending his own or somebody else's rights. The requirements of legitimate defense and its' contextualization are analyzed with the purpose of achieving a holistic understanding of this legal right and its' proper use by the operators of justice. This work is of great relevance at present, considering that it is a criminal-legal figure, very controversial for criminal justice operators, taking into account that some aspects are eminently subjective and that Ecuadorian legislation is regulated to defend their own rights. of which one defends or of third persons, nevertheless of which in other legislations, such as the Argentinean and Colombian, in spite of having similar aspects with the Ecuadorian one, in this last one is not regulated the legitimate defense to defend the private property, which is duly regulated in the laws of the two countries referred to above, an aspect that is very controversial since in this case two fundamental rights are faced, the one that is private property and on the other hand that physical integrity can be or the life of the person who enters the domicile of the person defending the property right.

Keywords: Legitimate defense, exclusion of unlawfulness, legal asset, current and illegitimate aggression, rational need, lack of provocation. 


\section{Introducción.}

La legítima defensa es una figura jurídica de carácter constitucional y penal, y una de sus características fundamentales es la de excluir la responsabilidad de la persona que se defiende, siempre que cumpla los requisitos que de manera expresa determina la ley, los cuales tienen relación con la agresión actual e ilegítima, la utilización de un medio racional para repeler la agresión, y la falta de provocación suficiente por parte del que se defiende.

La presente investigación tiene como finalidad realizar un estudio científico-jurídico desde el punto de vista constitucional, legal y doctrinario de la legítima defensa, con la finalidad de establecer de manera precisa los parámetros que son necesarios para que procesa la aplicación de esta figura jurídico-penal, considerando sus requisitos de orden legal.

Este trabajo investigativo, será desarrollado mediante la utilización de los métodos inductivo-deductivo y analítico-sintético, considerando que se parte de lo particular a lo general y viceversa, así como también realizar el respectivo análisis y síntesis de lo que constituye la legítima defensa dentro del Derecho Penal, tomando en cuenta los requisitos legales, las circunstancias en las que se verifica el hecho y las actuaciones de los dos sujetos que intervienen para que se configure la legítima defensa.

Este trabajo es de mucha relevancia en la actualidad, considerando que es una figura jurídico-penal, muy controvertida para los operadores de justicia en materia penal, tomando en cuenta que algunos aspectos son eminentemente subjetivos y que la legislación ecuatoriana está regulada para defender derechos propios del que se defiende o de terceras personas, sin embargo de lo cual en otras legislaciones, tales como la argentina y colombiana, a pesar de tener aspectos similares con la ecuatoriana, en esta última no se encuentra regulado la legítima defensa para 
defender la propiedad privada, lo que se encuentra debidamente regulada en las legislaciones de los dos países antes referidos, aspecto que es muy controvertido ya que en este caso se enfrentan dos derechos fundamentales, el uno que es la propiedad privada y por otra parte que puede ser la integridad física o la vida de la persona que ingresa al domicilio de la persona que defiende el derecho de propiedad.

Las metas trazadas por parte del autor de esta investigación, es lograr una explicación jurídica sobre lo que constituye la legítima defensa, sus requisitos legales, así como la materialización de dicha institución jurídico-penal, con la intervención de los operadores de justicia en materia penal, para lo cual se utiliza una bibliografía actualizada así como las normas jurídicas vigentes en Ecuador, para luego compararlas con las legislaciones de Argentina y Colombia y finalmente establecer tanto las semejanzas como las diferencias jurídicas, mediante un análisis cualitativo del tema materia de la presente investigación.

Tomando en cuenta la problemática de carácter jurídico, expresada en los párrafos anteriores, se realizó un estudio bibliográfico y legal, lo cual permitió el diseño teórico y marco teórico referencial de la presente investigación, cuyos aspectos de relevancia se presentan a continuación.

\section{Desarrollo}

\section{Metodología}

Para establecer la metodología, cabe recalcar que el fin de la investigación jurídica es la aplicación en esencia del derecho, para lo cual la interpretación es la herramienta pertinente para una operación intelectual en virtud de la que se puede dar sentido a un todo. 
(García Fernández, 2014) "De acuerdo a Kelsen, la interpretación es la determinación cognoscitiva de los significados de las normas jurídicas” (p.452).

En mención a lo citado, se ha elegido el método sistemático de la investigación jurídica, por cuanto de forma conceptual, expone lo siguiente.

Método sistemático. Que considera que la validez de una norma siempre está en otra norma, nunca en un hecho. El derecho es un conjunto de normas o un sistema, y no se puede captar la atención a una norma aislada. (García Fernández, 2014, pág. 452).

En lo referente a los materiales, la investigación jurídica contemporánea, permite establecer un enfoque dogmático, pues el ámbito teórico expone la problemática jurídica a percepción de las fuentes formales e históricas del derecho, pues no toma en cuenta los elementos fácticos, el objeto es el ordenamiento jurídico, pudiendo ser actual o precedente y el fin la aplicación eficaz de los elementos jurídicos.

\section{Resultados.}

Aspectos generales en la legítima defensa

La legítima defensa o defensa propia, constituye una de las causas de exclusión de la responsabilidad penal, se basa en el Derecho Natural, que tiene una persona para proteger sus bienes jurídicos que son parte del Derecho Penal, y es justificable cuando la víctima de la comisión de un delito del ejercicio público de la acción, se encuentra sin protección ante el agresor o victimario, y repele el ataque a su vez para evitar un daño respecto del derecho de propiedad o tenencia de sus bienes, su integridad física, su vida, su libertad sexual y cualquier otro bien jurídico protegido, que forme parte del catálogo de delitos que tipifica y sanciona la ley. 
Para que proceda la legítima defensa, es necesaria la concurrencia de los presupuestos establecidos en la normativa, en el caso ecuatoriano, en el artículo 33 del Código Orgánico Integral Penal, siendo fundamental hacer un estudio desde el punto de vista doctrinario a fin de alcanzar una comprensión integral de esta figura jurídica de carácter constitucional y legal.

Para la presencia de un delito es preciso un comportamiento humano subsumible en un tipo de conducta previsto en principio en la Parte Especial del Código Penal. Por ello no basta, pues puede suceder que tal comportamiento típico se halle justificado por la concurrencia de una causa de justificación. Faltará entonces la antijuricidad de la conducta y desaparecerá la posibilidad de considerar que la misma constituya delito. (Mir Puig, 2014, pág. 421)

Siguiendo la misma línea de Mir Puig, para que un acto humano constituya delito, es necesario que sea típico, antijurídico y culpable, pero cuando se hace referencia a la legítima defensa, falta uno de los elementos constitutivos del delito anteriormente mencionado, que en este caso es la antijuricidad de la conducta, consecuentemente si la víctima de la comisión de una infracción hace uso de la legítima defensa cumpliendo las reglas correspondientes, referentes a esta figura jurídico penal, no le es atribuible responsabilidad en el campo penal, es por ello que las diferentes legislaciones penales del mundo han dictado normas legales que determinan en forma clara y precisa los requisitos que se deben cumplir para que se configure una verdadera legítima defensa.

En este mismo orden de ideas Cerezo Mir, al referirse al tema en estudio afirma que:

El fundamento de la eximente de la legítima defensa se halla, en primer lugar, en la necesidad de defender los bienes jurídicos frente a una agresión. Por otra parte, al impedir o 
repeler una agresión ilegítima se defiende el ordenamiento jurídico. La legítima defensa tiene, pues, un doble fundamento. No basta la simple necesidad de defender un bien jurídico, pues se exige que la agresión sea ilegítima...Por agresión debe entenderse la realización de una acción dirigida a la producción de la lesión de un bien jurídico. La simple omisión, es decir, la no realización de una acción que podía realizar el sujeto, en la situación concreta en que se hallaba, no constituye una agresión. Pues en ella falta la causalidad y la voluntad de realización finalidad. (Cerezo Mir, 2013, pág. 521)

Podría decirse que la legítima defensa, se refiere a una concesión del Estado al individuo para proteger sus derechos, es decir el uso de la violencia privada por parte del ciudadano para precautelar un bien jurídico protegido, cuando éste puede ser gravemente vulnerado, siempre y cuando exista necesidad de defenderlo y la agresión inminente sea actual, ilegítima, que el medio utilizado sea el racional para repelerla, y que no exista provocación suficiente de quien se defienda.

La necesidad, como justamente destacó Armin KAUFMANN, es un principio estructural y, naturalmente, esencial en la legítima defensa, gobernado, como es sabido, por el criterio de carácter objetivo y económico de menor lesividad (Iglesias Rio, 1999, pág. 405).

En consecuencia, constituye un elemento esencial de la legítima defensa, la necesidad que tiene la víctima para defenderse ante la inminente afectación de un bien jurídico protegido, ejercida por el victimario, en cuyo caso la intervención oportuna de la persona que se defiende evita la lesividad de ese bien jurídico.

Se entenderá por ilegítima cuando esta sea antijurídica, infrinja el ordenamiento jurídico y por ende, represente un ilícito de conducta y hacer temer el ilícito resultado. La agresión ilegítima puede provenir de una persona no culpable o no punible; puesto que estas también 
pueden actuar de manera antijurídica, y restringir el concepto de agresión ilegítima significará limitar el ámbito de la legítima defensa; por ejemplo es admisible la legítima defensa frente al ataque de personas ebrias, tóxico-maníacas, enfermos mentales. (García Falconí, 2014, pág. 460).

Por lo expresado anteriormente, el autor de esta investigación concuerda con García, porque efectivamente existirá necesidad de defender un bien jurídico, en cuanto la reacción autorizada por el ordenamiento jurídico es indispensable para salvar el interés del agredido, encaminado al amparo de sus derechos tutelados por el Derecho Penal. Mientras que para que exista agresión ilegítima debe representar un injusto en los términos del hecho punible, siempre que la agresión venga del sujeto activo de la infracción y la legítima defensa sea ejercida en ese mismo instante por parte de la víctima o de la persona que se defiende.

\section{Causas de exclusión de la antijuricidad}

Uno de los elementos del delito es la antijuricidad, al referirse a una acción que está contra el ordenamiento jurídico, dicho de otra manera, es la amenaza o lesión, sin causa justa, a un bien jurídico protegido por la ley penal. No existe antijuricidad y por ende infracción penal, si la conducta típica, es justificada en la aplicación del estado de necesidad o en la legítima defensa, siendo éstas dos figuras jurídico-penales, eximentes de responsabilidad penal.

Las causas de exclusión de la antijuricidad, también denominadas de justificación, se encuentran reguladas en los artículos 30, 32 y 33 del Código Orgánico Integral Penal, las cuales son: cuando se actúa en cumplimiento de una orden legítima y expresa de autoridad competente o de un deber de orden legal; el estado de necesidad; y, la legítima defensa que consiste cuando una persona 
actúa en defensa de cualquier derecho propio o ajeno siempre que se cumplan los requisitos del cuerpo legal antes referido.

De las disposiciones legales anteriormente referidas, se desprende que existen tres instituciones jurídico penales, que constituyen mecanismos que eximen de responsabilidad a la persona que realice un acto en defensa de sus bienes jurídicos protegidos, siendo las más relevantes el estado de necesidad y la legitima defensa, que debe cumplir requisitos propios o exclusivos para su procedencia, lo cuales se encuentran regulados en la legislación penal ecuatoriana.

Se puede concluir, en cuanto a las causas de justificación reguladas por ley, que ellas tienen principios en sí las hacen flexibles, tal como puede verse en el estado de necesidad, cuya base es la ponderación de intereses y la legítima defensa en cuanto se tiene en cuenta el principio de autoprotección y de prevalencia del Derecho (Donna, 2006, pág. 395)

Es preciso diferenciar el estado de necesidad de la legítima defensa, el primero no requiere que exista una víctima de agresión en curso, ni una persona agresora de quien defenderse, implica el sacrificio de un bien jurídico considerado de menor valoración objetiva (ponderación), se habla del interés social de la acción salvadora; mientras que en la segunda, si hay agresión ilegítima de una persona a otra, puede sucumbir el bien jurídico protegido más importante (no ponderación), se trata de un interés particular, que en este caso es del que se defiende ante una agresión inminente de quien violenta el derecho del primero.

Así como tienen diferencias, el estado de necesidad y la legítima defensa, también tienen similitudes: las dos son eximentes de responsabilidad penal, solamente proceden si se utiliza el medio menos lesivo, el atacado debe encontrarse en situación de peligro real y de manera 
particularizada en la legislación penal ecuatoriana deben cumplirse los presupuestos que están determinados en el Código Orgánico Integral Penal.

\section{Justificación del resultado}

El derecho a la legítima defensa actualmente se basa en dos principios: la protección individual y el prevalecimiento del Derecho. Es decir: en primer lugar, la justificación por legítima defensa presupone siempre que la acción típica sea necesaria para impedir o repeler una agresión antijurídica a un bien jurídico individual; la legítima defensa es para el “particular un derecho protector duro y enraizado en la convicción jurídica del pueblo". De ello se puede derivar ya diversas consecuencias que son importantes para la interpretación del derecho de legítima defensa. (Roxin, 1997, pág. 608).

Concordando con Roxin, efectivamente la legítima defensa se basa en los principios de protección individual y prevalencia del Derecho, vale decir, que la justificación por legítima defensa tiene su efectiva vigencia siempre que el acto humano ejercido por quien se defiende sea necesario para impedir una agresión ilegítima con el único fin de evitar la vulneración de un bien jurídico protegido, el mismo que le corresponde exclusivamente al que ejercita este derecho y por ende es de carácter individual, y, por otro lado también la legítima defensa cristaliza la materialización de la defensa del Derecho como ciencia, ante una agresión, que si bien es cierto afecta a un bien jurídico de carácter individual, que en este caso es del que se defiende, no es menos cierto que se garantiza la plena vigencia del Derecho, siendo el único que garantiza la convivencia pacífica de los pueblos. 


\section{Requisitos legales}

Los requisitos legales para que opere la legítima defensa en la legislación ecuatoriana, se encuentran determinados en el artículo 33 del Código Orgánico Integral Penal.

\section{Agresión actual e ilegítima}

A la dogmática alemana sólo contados autores mantuvieron a partir de la segunda mitad del siglo XIX que agresión implica el empleo de fuerza, de violencia. En todo su rigor sólo mantienen esta postura KRUG, H.MAYER, quienes no sólo exigen que la agresión sea violenta, sino además dirigida contra la persona, y GLASER, pues SCHAPER mantiene que por regla general la agresión ha de ser violenta, pero reconoce que son imaginables acciones sin violencia que sean agresiones. (Luzón Peña, 2015, pág. 115)

Existe cierta controversia respecto a que si la agresión ilegítima que atenta contra un bien jurídico protegido, debe ser siempre dolosa o solamente culposa (incumplir el deber objetivo de cuidado); para que proceda la legítima defensa, la ley solamente exige que sea antijurídica, ante esta realidad, tanto las conductas dolosas como culposas son antijurídicas, otro tema en discusión es si dicha conducta se realiza o no con voluntad y conocimiento, y si el punto de vista de quien va a ejercer la legitima defensa se basa en juicios objetivos o subjetivos. Todos estos aspectos en debate, hacen que la legítima defensa sea una institución jurídica - penal controversial.

\section{Necesidad racional de la defensa}

Es ineludible que la acción defensiva sea racionalmente necesaria, sin que el daño que se produzca de la protección del bien jurídico que se defiende, sea mayor al necesario para impedir o repeler el ataque. La preponderancia de los intereses no se mide con criterio de valuación material, 
sino que responde a una valuación jurídica, que corresponde a los juzgadores analizar, de acuerdo al caso concreto, no se trata de una operación aritmética, sino de verificar si se cumple o no con el objetivo de salvaguardar el bien jurídico en peligro.

Esta necesidad racional de defensa, debe ser analizada con sana critica por los juzgadores, sin caer en criterios subjetivos, debiendo dictar, fallos motivados que justifiquen su evaluación de dicha necesidad, analizando cada una de las acciones realizadas tanto por el agresor como por la víctima que intenta justificación, a través de la legítima defensa.

\section{Falta de provocación suficiente por parte de quien actúa en defensa del derecho}

La provocación puede consistir en una acción o en una omisión. La acción no es preciso esté dirigida al fin de desencadenar la respuesta agresora. No es preciso siquiera que la respuesta agresora sea una consecuencia prevista como necesaria por el provocador o que éste considere posible y con cuya producción cuente; es decir, no es necesario que la respuesta agresora esté comprendida en la voluntad de realización del provocador". Es necesario, además que exista una proporción o equivalencia entre la respuesta agresora y la provocación, para que esta última pueda estimarse suficiente. (Cerezo Mir, 2013, pág. 556)

Si la víctima fue quien induce a la agresión, no cabe que para eximir su culpabilidad por el daño ocasionado, argumente la existencia de legítima defensa, pues constituye un requisito esencial la falta de provocación suficiente por parte de quien se defiende, porque de no ser así, no se estaría frente a una legítima defensa, a pesar de encontrarse los otros dos requisitos que forman parte de esta institución jurídico penal, en consecuencia, es necesario que se cumplan las tres reglas expresamente determinados en la ley, a fin de que el fiscal, como titular del ejercicio público de la acción se abstenga de acusarle a la persona que se defendió y de esa forma el juzgador dicte un auto 
de sobreseimiento, en el caso de que ya se haya iniciado la instrucción por parte del fiscal y de poderse determinar la legítima defensa antes del inicio del proceso penal, le correspondería a la Fiscalía General del Estado iniciar una investigación previa, mediante la cual se obtenga elementos de convicción suficientes como para establecer que en un caso concreto existió o no legítima defensa.

Relevancia de la legítima defensa

La legítima defensa ya no es vista como en la antigüedad, como una institución caprichosa que resguardaba el instinto de conservación, sino como una institución jurídico - penal, debidamente reglada, como un medio que coadyuva a la función pacificadora del derecho, en su búsqueda de la justicia.

En el devenir del tiempo, han existido ciertas confusiones respecto a la legítima defensa, hasta que, en la actualidad, ha logrado justificar su existencia en sí misma. Para Aguilar.

La naturaleza de la defensa legítima como causa de justificación parece fuera de duda, pero durante mucho tiempo estuvo confundida con las causas de inculpación, planteándose como problema de miedo o de perturbación del ánimo, en el que se defiende porque es objeto de un ataque. De modo que quien actúa en defensa legítima, lleva a que su conducta sea lícita, es decir, jurídica, por la exclusión de la antijuricidad. (Aguilar López, 2015, pág. 311)

Todo interés legítimamente protegido, puede ser objeto de legítima defensa al concebirse como un eximente de responsabilidad, debe ser tratada con la importancia que amerita, verificando si en su aplicación se han cumplido todos los presupuestos necesarios para ejercerla, pues no se puede admitir un abuso de tan progresista institución jurídica que busca precautelar bienes jurídicos 
protegidos, dotándole a los particulares, una parte del poder del Estado, cuando las circunstancias lo ameriten, conforme a Derecho.

El actual requisito exigido por el COIP, que ya se encontraba en el Código Penal de 1938, es compartido por diferentes legislaciones como la española, argentina, peruana y chilena; señalando que para que dé lugar la invocación de la legítima defensa será necesario que quien se defienda no haya provocado la agresión de manera suficiente; mientras que en las legislaciones: italiana, alemana, francesa y colombiana no las contemplan, debido a que no tienen el carácter de fundamental; por lo que si sólo falta el mismo cabe la atenuación propia de la eximente incompleta; salvo cuando la provocación sea intencional buscando la agresión cuyo caso se denegaría también esta eximente” (García Falconí, 2014, pág. 461)

De lo expresado por García, se infiere que, sobre la regulación de la legítima defensa, existen legislaciones similares a la ecuatoriana tales como la española, peruana, argentina y chilena, respecto de uno de los requisitos básicos para que proceda este eximente de responsabilidad penal; mientras que, en otras legislaciones italiana, alemana, francesa y colombiana, no exigen el requisito antes referido para que proceda la legítima defensa.

Es fundamental en la presente investigación, hacer un estudio comparativo, respecto de la legítima defensa, con la legislación argentina, cuya figura jurídica se encuentra regulada en el art. 34.6 del Código Penal de la Nación, siendo procedente cuando haya agresión ilegítima, necesidad racional del medio empleado para impedirla y falta de provocación suficiente de parte del que se defiende, diferenciándose por lo tanto de la legislación ecuatoriana sobre el primer requisito que es agresión actual e ilegítima, lo cual permite obtener una diferencia jurídica determinante, ya que el que se defiende debe hacer uso de la legítima defensa en el mismo momento de la agresión 
ilegítima, aspecto que no está regulado en la legislación argentina, pero ésta última hace referencia a una circunstancia, esto es que durante la noche la persona que se defiende puede rechazar el escalamiento o fractura de cercados, paredes o entradas a una casa habitada, sin importar el daño ocasionado al agresor, aspecto que no se encuentra regulado en la legislación penal del Ecuador.

Desde el punto de vista jurídico, de la legislación colombiana tiene reglas que regulan la legítima defensa y concretamente se encuentra regulada en el artículo 32.6 del Código Penal, donde se expresa que la persona que se defienda obre por necesidad de defender un derecho propio o ajeno, contra una agresión actual e inminente, siempre que la misma sea proporcional a la agresión, requisitos que son similares a la legislación ecuatoriana, excepto el determinado en el artículo 33.3 del COIP del Ecuador, que tiene relación con la falta de provocación suficiente por parte del que se defiende, aspecto que no se encuentra regulado por la legislación colombiana, pero en cambio regula que constituye legítima defensa cuando el agresor intenta penetrar o haya penetrado a su habitación o independencias inmediatas, teniendo similitud sobre este aspecto con la legislación argentina.

\section{Discusión de Resultados.}

La legítima defensa, se refiere a una concesión del Estado al individuo para proteger sus derechos, es decir el uso de la violencia privada por parte del ciudadano para precautelar un bien jurídico protegido, cuando éste puede ser gravemente vulnerado, siempre y cuando exista necesidad de defenderlo y la agresión inminente sea actual e ilegítima, que el medio utilizado sea el racional para repelerla, y que no exista provocación suficiente de quien se defienda. En mención de lo que se expresa como una concesión del estado, es pertinente recalcar por lo expuesto a los resultados obtenidos, que a necesidad es el elemento principal para que exista dicha concesión, tal es la esencialidad del concepto de antijuricidad, que esta constando uno de los elementos principales del 
delito, siendo este un hecho típico, antijurídico y punible, pues si no cumpliere con alguno de estos elementos, un hecho no puede tener la configuración de delito.

La necesidad que tiene la víctima para defenderse ante la inminente afectación de un bien jurídico protegido, ejercida por el victimario, en cuyo caso la intervención oportuna de la persona que se defiende evita la lesividad de ese bien jurídico.

Para que exista agresión ilegítima debe representar un injusto en los términos del hecho punible, siempre que la agresión venga del sujeto activo de la infracción y la legítima defensa sea ejercida en ese mismo instante por parte de la víctima o de la persona que se defiende.

Uno de los elementos del delito es la antijuricidad, al referirse a una acción que está contra el ordenamiento jurídico, dicho de otra manera, es la amenaza o lesión, sin causa justa, a un bien jurídico protegido por la ley penal. No existe antijuricidad y por ende infracción penal, si la conducta típica, es justificada en la aplicación del estado de necesidad o en la legítima defensa, siendo éstas dos figuras jurídico-penales, eximentes de responsabilidad penal.

Es preciso diferenciar el estado de necesidad de la legítima defensa, el primero no requiere que exista una víctima de agresión en curso, ni una persona agresora de quien defenderse, implica el sacrificio de un bien jurídico considerado de menor valoración objetiva (ponderación), se habla del interés social de la acción salvadora; mientras que en la segunda, si hay agresión ilegítima de una persona a otra, puede sucumbir el bien jurídico protegido más importante (no ponderación), se trata de un interés particular, que en este caso es del que se defiende ante una agresión inminente de quien violenta el derecho del primero. 
Existe cierta controversia respecto a que si la agresión ilegítima que atenta contra un bien jurídico protegido, debe ser siempre dolosa o solamente culposa (incumplir el deber objetivo de cuidado); para que proceda la legítima defensa, la ley solamente exige que sea antijurídica, ante esta realidad, tanto las conductas dolosas como culposas son antijurídicas, otro tema en discusión es si dicha conducta se realiza o no con voluntad y conocimiento, y si el punto de vista de quien va a ejercer la legitima defensa se basa en juicios objetivos o subjetivos. Todos estos aspectos en debate, hacen que la legítima defensa sea una institución jurídica - penal controversial.

Es ineludible que la acción defensiva sea racionalmente necesaria, sin que el daño que se produzca de la protección del bien jurídico que se defiende, sea mayor al necesario para impedir o repeler el ataque.

Si la víctima fue quien induce a la agresión, no cabe que para eximir su culpabilidad por el daño ocasionado, argumente la existencia de legítima defensa, pues constituye un requisito esencial la falta de provocación suficiente por parte de quien se defiende, porque de no ser así, no se estaría frente a una legítima defensa, a pesar de encontrarse los otros dos requisitos que forman parte de esta institución jurídico penal, en consecuencia, es necesario que se cumplan las tres reglas expresamente determinados en la ley, a fin de que el fiscal, como titular del ejercicio público de la acción se abstenga de acusarle a la persona que se defendió y de esa forma el juzgador dicte un auto de sobreseimiento

\section{Conclusiones.}

La legítima defensa es una figura jurídico-penal, que permite defender derechos propios o ajenos, siempre que se cumplan los requisitos expresamente determinados en la ley, es decir que el 
acto humano de parte del agresor y de la persona que se defiende cumplan los presupuestos de orden jurídico determinados en el artículo 33 del Código Orgánico Integral Penal.

Es indiscutible que la legítima defensa se encuentra regulada de manera diversa en las legislaciones penales de los diferentes países del mundo, por lo que, tomando en cuenta la globalización del Derecho como ciencia, es necesario realizar este tipo de investigaciones, para que luego de establecer diferencias y semejanzas, otorgar al legislador los elementos jurídicos pertinentes y así dicte leyes que protejan en igualdad de condiciones los derechos de las personas que se defienden.

\section{Bibliografia.}

Aguilar López, M. A. (2015). El Delito y la Responsabilidad Penal. México: Porrúa.

Cerezo Mir, J. (2013). Derecho Penal. Buenos Aires: Tecnos Grupo Anaya S.A.

Código Penal de la Nación Argentina, Ley 11.179 (T.O. 1984 actualizado)

Código Penal Colombiano, Ley 5999 de 2000

Código Orgánico Integral Penal, publicado en el Registro Oficial suplemento Año I-Nº 18010 de febrero de 2014

Donna, E. (2006). Derecho Penal. Colombia: Santa Fé.

García Falconí, J. (2014). Código Orgánico Integral Comentado. Quito: Latitud 0.

García Fernández, D. (2014). La Metodología de la investigación jurídica en el Siglo XXI. Mexico: UNAM.

Iglesias Rio, M. A. (1999). Fundamento y Requisitos Estructurales de la Legítima Defensa. Granada: Comares.

Luzón Peña, D. (2015). Aspectos esenciales de la legítima defensa. Buenos Aires: S.R.L.

Mir Puig, S. (2014). Derecho Penal. Barcelona: Reppertor.

Roxin, C. (1997). Fundamentos, estructura del delito. Madrid: Civitas. 